Title:

Transmission Electron Microscopy Characterization of the Fission Gas Bubble Superlattice in Irradiated U-7wt\%Mo Dispersion Fuels

Authors names and affiliations:

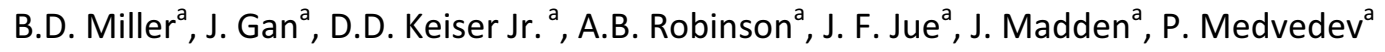

${ }^{a}$ Idaho National Laboratory, 2525 Fremont Ave., Idaho Falls, ID 83401

\title{
Corresponding author
}

Dr. Dennis D. Keiser, Jr.

Nuclear Fuels and Materials Division

Idaho National Laboratory

P.O. Box 1625

Idaho Falls, ID, U. S. A. 83415-6188

Phone: 1 (207) 533-7298

Fax: 1 (208) 533-7863

E-mail: Dennis.Keiser@inl.gov

\section{Abstract:}

Transmission electron microscopy characterization of irradiated $\mathrm{U}-7 \mathrm{wt} \% \mathrm{Mo}$ dispersion fuel were performed on various U-Mo fuel samples to understand the effect of irradiation parameters (fission density, fission rate, and temperature) on the self-organized fission-gas-bubble superlattice that forms in the irradiated U-Mo fuel. The bubble superlattice was seen to form a face centered cubic structure coherent with the host $\mathrm{U}-7 \mathrm{wt} \% \mathrm{Mo}$ body-centered cubic structure. At a fission density between 3.0 and $4.5 \times 10^{21} \mathrm{fiss} / \mathrm{cm}^{3}$, the superlattice bubbles appear to have reached a saturation size with additional fission gas associated with increasing burnup predominately accumulating along grain boundaries. At a fission density of $\sim 4.5 \times 10^{21}$ fiss $/ \mathrm{cm}^{3}$, the $\mathrm{U}-7 \mathrm{wt} \% \mathrm{Mo}$ microstructure starts to undergo grain subdivision and can no longer support the ordered bubble superlattice. The sub-divided fuel grains are less than $500 \mathrm{~nm}$ in diameter with what appears to be micron-size fission-gas bubbles present on the grain boundaries. Solid fission products typically decorate the inside surface of the micron-sized fission-gas bubbles. Residual superlattice bubbles are seen in areas where fuel grains remain micron sized. Potential mechanisms of the formation and collapse of the bubble superlattice are discussed.

\section{Introduction:}

Understanding fuel performance under irradiation is a key aspect to qualifying nuclear fuel. The High Performance Research Reactor Fuel Development program (HPRRFD), formally known as the Reduced Enrichment for Research and Test Reactors (RERTR) program, was tasked to develop a high-density, lowenriched uranium fuel $\left(<20 \% \mathrm{U}^{235}\right)$ to reduce the demand of highly enriched uranium in research reactors for the Global Threat Reduction Initiative (GTRI) [1]. The primary fuel being studied is a U-xMo $(x=7-10$ wt\%) based fuel with the $U-7 w t \% M o$ being the primary focus of this paper. The two major fuel forms are U-Mo/Al dispersion fuel and U-Mo monolithic fuel in plate form [2,3]. Dispersion fuels typically contain $\mathrm{U}-7 \mathrm{wt} \% \mathrm{Mo}$ fuel spheres embedded in an Al-alloy matrix. The Al matrix is often $\mathrm{Si}$ enriched to suppress the fuel-matrix interaction (FMI) layer that forms during fuel fabrication and irradiation [2]. Monolithic fuels are primarily U-10wt\%Mo foils rolled to a thickness of roughly $250 \mu \mathrm{m}$. 
This foil is secured in Al cladding. The cladding is often bonded to the fuel by hot isostatic pressing [3]. A Zr foil can be used as a diffusion barrier between the fuel foil and the cladding to mitigate FMI layer growth [3].

Post-irradiation examination (PIE) of both the dispersion and monolithic fuels shows that the FMI layer formed during fabrication and/or by irradiation is a key feature that needs to be fully understood to qualify the U-Mo fuel design. Various studies have been performed on the FMI layer to characterize the irradiation behavior of this layer [4-8]. In addition to the FMI layer, characterization of the fuel region is an important aspect of fuel qualification. PIE of the fuel region in dispersion fuels shows two distinct fuel microstructures: a low fission density microstructure and a high fission density microstructure with the transition of the two microstructures occurring around a fission density of $4.5 \times 10^{21} \mathrm{fiss} / \mathrm{cm}^{3}$ [9]. This microstructural transition can be correlated to the increased rate of swelling around $4.5 \times 10^{21} \mathrm{fiss} / \mathrm{cm}^{3}$ seen in the SELENIUM and E-FUTURE experiments $[10,11]$. It is known that the monolithic fuel displays a similar swelling transition as seen in the dispersion fuels above a fission density of $7 \times 10^{21} \mathrm{fiss} / \mathrm{cm}^{3}$ [12]. The low-fission-density microstructure of dispersion fuels is dominated by fission-gas bubbles on the grain boundaries of the fuel and a self-organized bubble superlattice in the grain interior $[4,6,9]$. The high-fission-density microstructure shows randomly distributed micron-sized fission-gas bubbles distributed throughout the grains with residual bubble superlattice seen in micron-sized grains that remain in the fuel [9].

Ordered bubble superlattices have been seen before in ion-irradiated materials [13-24]. Typical bubble sizes and spacings in these bubble superlattices are in the range of 2-6.4 $\mathrm{nm}$ and 4-12 $\mathrm{nm}$, respectively $[17,18,22]$. Common observations of the ion-induced bubble superlattices show that the superlattice will primarily form in the same structure and crystal orientation as the host material, with some variants seen in various materials $[14,20,24]$. Typical ordering of the ion-irradiated bubble superlattices tends to result in a superlattice constant in the 10's of nanometers.

The goal of this article is to discuss the work performed to characterize the bubble superlattice in U$7 w t \% M o$ dispersion fuel at the Idaho National Laboratory. Four separate U-7wt\%Mo dispersion fuel samples were examined to study the bubble superlattice's microstructure. This examination included four samples with fission densities of 3.0, 3.3, 4.5, and $5.2 \times 10^{21} \mathrm{fiss} / \mathrm{cm}^{3}$. Characterization of the bubble superlattice includes: measuring parameters of the bubble superlattice (superlattice constant and bubble size), changes of the bubble superlattice physical parameters as a function of irradiation parameters, and the microstructural observations on the collapse of the bubble superlattice at fission densities above $4.5 \times 10^{21} \mathrm{fiss} / \mathrm{cm}^{3}$. Potential mechanisms of how the superlattice forms and collapses will be discussed.

\section{Experimental Setup:}

Transmission electron microscopy (TEM) samples of irradiated U-7wt\%Mo were obtained from three irradiated dispersion fuel plates. The TEM samples were created from the $1 \mathrm{~mm}$ diameter cylindrical punchings produced from the $1.5 \mathrm{~mm}$ thick fuel plates. The punchings were created at the Hot Fuels Examination Facility (HFEF) at Idaho National Laboratory (INL) using a hydraulic press. The samples were then shipped to the Electron Microscopy Laboratory (EML) for TEM sample preparation and microstructural characterization. Additional information on the punching process can be found in [25]. TEM samples were created by two different methods. One method involved securing the samples in a 3 $\mathrm{mm}$ diameter molybdenum ring with a $1 \mathrm{~mm}$ hole bored out of the center. The ring was mechanically polished to a thickness of $\sim 150 \mu \mathrm{m}$ and then electrically jet-polished to further reduce the thickness in 
the middle. As a final step, a Gatan precision ion polishing system (PIPS) was used to mill the thin area to create TEM-transparent regions for microstructural characterization.

The other method for creating TEM samples is using a FEI Quanta 3D w/Omniprobe dual-beam focused ion beam (FIB) located at EML. An irradiated fuel sample is first mounted and mechanically polished on its side to its mid-plane. Samples were polished to a $0.25 \mu \mathrm{m}$ mirror finish. The polished samples were first imaged in a scanning electron microscope (SEM) and then loaded into the FIB. TEM samples were obtained using the FIB lift-out techniques in $\mathrm{U}-7 \mathrm{wt} \% \mathrm{Mo}$ fuel areas deemed to be representative of the irradiated dispersion fuel. To aid in determining the representative areas of the fuel, cross-sections of the fuel were created to verify that the microstructure on the SEM level was consistent where TEM lamellas were created. Additional information describing the FIB liftout technique on irradiated fuel can be found in [26]. The TEM characterizations were carried out using a JEOL-2010 TEM/STEM, with a LaB 6 filament, operating at $200 \mathrm{keV}$.

Table 1 provides the irradiation parameters of the various TEM samples that were analyzed. Note that these samples are all U-7wt\%Mo dispersion fuels with varying matrix compositions. In plate R3R050, multiple samples were created at various locations in the plate and are designated as high and low for a high- and low-fission-density microstructure, respectively. Sample R2R010 was irradiated in the RERTR6 irradiation campaign [27]. Samples R2R040 and R3R050 were irradiated in the RERTR-7 irradiation campaign [28]. Various scanning electron microscopy characterization of these fuel samples can be seen in [2]. Transmission electron microscopy characterization has been previously reported and various information will be included in the results sections to provide comparison between samples for the discussion section $[6,27,29]$.

Table 1: Irradiation parameters of the U-7wt\%Mo fuel punchings analyzed in the TEM

\begin{tabular}{|c|c|c|c|c|}
\hline Fuel & U-7Mo/Al-2Si & U-7Mo/Al-2Si & U-7Mo/Al-5Si & U-7Mo/Al-5Si \\
\hline Fuel Plate ID & R2R010 & R2R040 & R3R050 (low) & R3R050 (high) \\
\hline $\mathrm{U}^{235}$ Enrichment & $19 \%$ & $58 \%$ & $58 \%$ & $58 \%$ \\
\hline $\begin{array}{c}\text { Local Fission Density }\left(10^{21}\right. \\
\left.\text { fiss } / \mathrm{cm}^{3}\right)\end{array}$ & 4.5 & 3.3 & 3.0 & 5.2 \\
\hline $\begin{array}{c}\text { Time Averaged Fission Rate } \\
\left(10^{14} \text { fiss } / \mathrm{cm}^{2} \text {-s) }\right.\end{array}$ & 3.8 & 4.3 & 3.9 & 6.6 \\
\hline $\begin{array}{c}\text { Plate Centerline } \\
\text { Temperature }\left({ }^{\circ} \mathrm{C}\right)\end{array}$ & 109 & 91 & 103 & 130 \\
\hline
\end{tabular}

\section{Results:}

Prior to discussing effects of various irradiation parameters on the bubble superlattice, common observations of the bubble superlattice will be presented. The bubble superlattice is coherent with the host U-7wt\%Mo fuel forming a face-centered cubic structure (fcc). U-7wt\%Mo is a body centered cubic structure (bcc) with a lattice constant of $3.43 \mathrm{~nm}$ [30]. Coherency was found from the selected area diffraction patterns where the satellite spots from the bubble superlattice are present. In addition to the bright-field images, the diffraction spots of the $\mathrm{U}-7 \mathrm{wt} \% \mathrm{Mo}$ structure show satellite spots around the 
individual U-7wt\%Mo diffraction spots, indicating ordering of the bubble superlattice and the coherency of the bubble superlattice. Long range ordering was on the micron length scale across the entire fuel grain. Figure 1 shows a bright-field image of the bubble superlattice with its corresponding diffraction patterns and satellite spots at a zone [110] diffraction condition from sample R2R010 with some images previously reported in [31]. It should be noted that no variations in the superlattice structure were seen during TEM characterization, with all TEM areas exhibiting an fcc structure. Figure 2 shows the brightfield images of typical bubble superlattices at a zone [110] diffraction condition from samples a) R3R050 (Low), b) R2R040, and c) R2R010. Obtaining high-quality images of the zone [100] and [111] is difficult with clear large ordering of the superlattice hard to come by. Figure 3) shows the bubble superlattice in sample R2R010 at the three major zones: a)zone [110], b) [100], and c) [111].

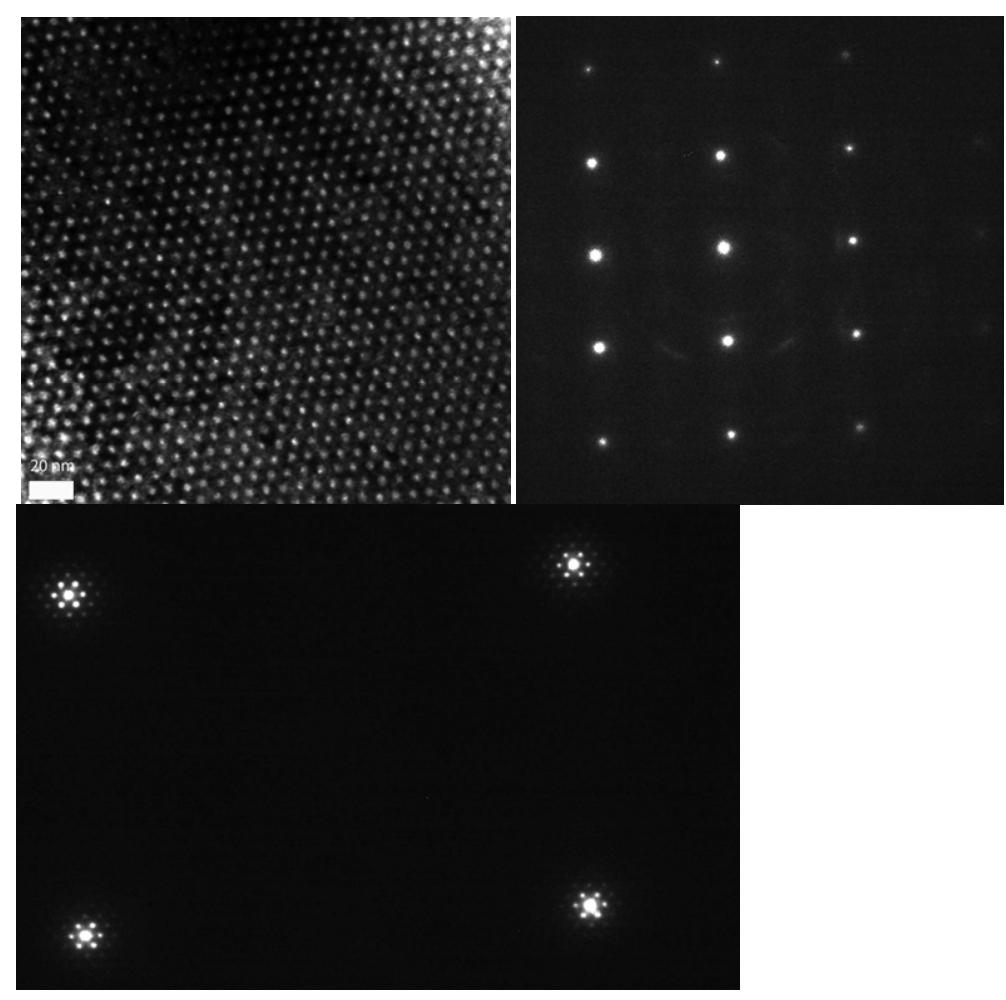

Figure 1: Bright-field micrograph of the bubble superlattice (left) with diffraction patterns at zone [110] (center), and (right) a magnified view of [110] diffraction pattern showing satellite spots corresponding to the bubble superlattice from sample R2R010 [31]. Note that R2R010 has a fission density of $4.5 \times 10^{21}$ fiss $/ \mathrm{cm}^{3}$. 


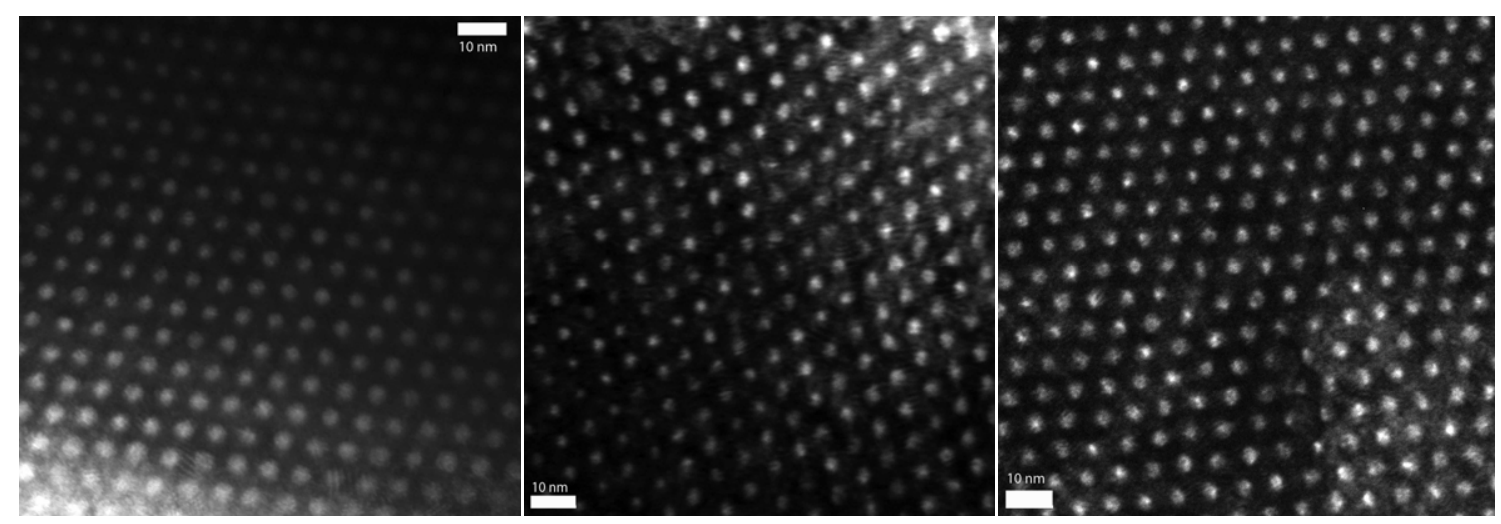

Figure 2: Bright-field micrographs of the bubble superlattice in (left) R3R050 (low), (center) R2R040, and (right) R2R010. The fission densities for R3R050 (low), R2R040, and R2R010 are 3.0, 3.3, and 4.5×10 21 fiss $/ \mathrm{cm}^{3}$ respectively.
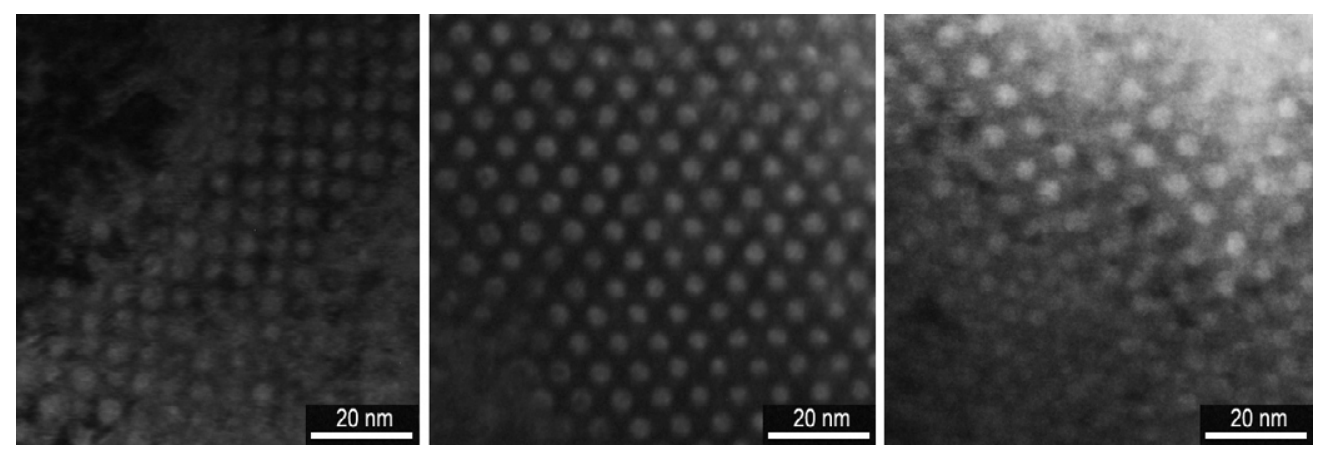

Figure 3: Bright-field micrographs of the bubble superlattice from sample R2R010 (left) at zone [110], (center) at zone [100], and (right) at zone [111]. R2R010 has a fission density of $4.5 \times 10^{21} \mathrm{fiss} / \mathrm{cm}^{3}$.

It should be noted that the bubble features in a TEM bright-field images show the projection of a row of superlattice bubbles stacked on each other. The TEM images are a two-dimensional (2D) representation of the real three-dimensional bubble superlattice. This stacking phenomenon presents issues in measuring the true bubble size of superlattice bubbles as a slight variation in spatial alignment of the bubbles will cause the 2D bubble in the TEM image to appear larger than the true size of the bubble. In addition to the size issue, the stacking makes it hard to tell whether the bubbles are faceted, which could affect how they form. To determine the size of the superlattice bubbles, bubble sizes were measured at the zone [110] condition, with as many bubbles measured in order to reduce the statistical error of the measurements. Table 2 shows the superlattice bubble sizes in the $\mathrm{U}-7 \mathrm{wt} \% \mathrm{Mo}$ fuel at various fission densities. In addition to the bubble size, the lattice constant of each bubble superlattice was determined, and these values are provided in Table 2 [31]. Figure 4 shows a typical superlattice bubble size distribution from R2R010 with a fission density of $\sim 4.5 \times 10^{21} \mathrm{fiss} / \mathrm{cm}^{3}$. 
Table 2: Bubble superlattice size and spacing at various fission densities [31]

\begin{tabular}{|c|c|c|c|}
\hline Fuel & U-7Mo/Al-5Si & U-7Mo/Al-2Si & U-7Mo/Al-2Si \\
\hline Fuel Plate ID & R3R050 (low) & R2R040 & R2R010 \\
\hline Local Fission Density $\left(10^{21}\right.$ fiss $\left./ \mathrm{cm}^{3}\right)$ & 3.0 & 3.3 & 4.5 \\
\hline Bubble Superlattice Diameter $(\mathrm{nm})$ & 3.6 & 3.1 & 3.5 \\
\hline Standard Deviation $(\mathrm{nm})$ & 0.4 & 0.5 & 0.4 \\
\hline Superlattice Constant $(\mathrm{nm})$ & 12.0 & 12.1 & 11.1 \\
\hline
\end{tabular}

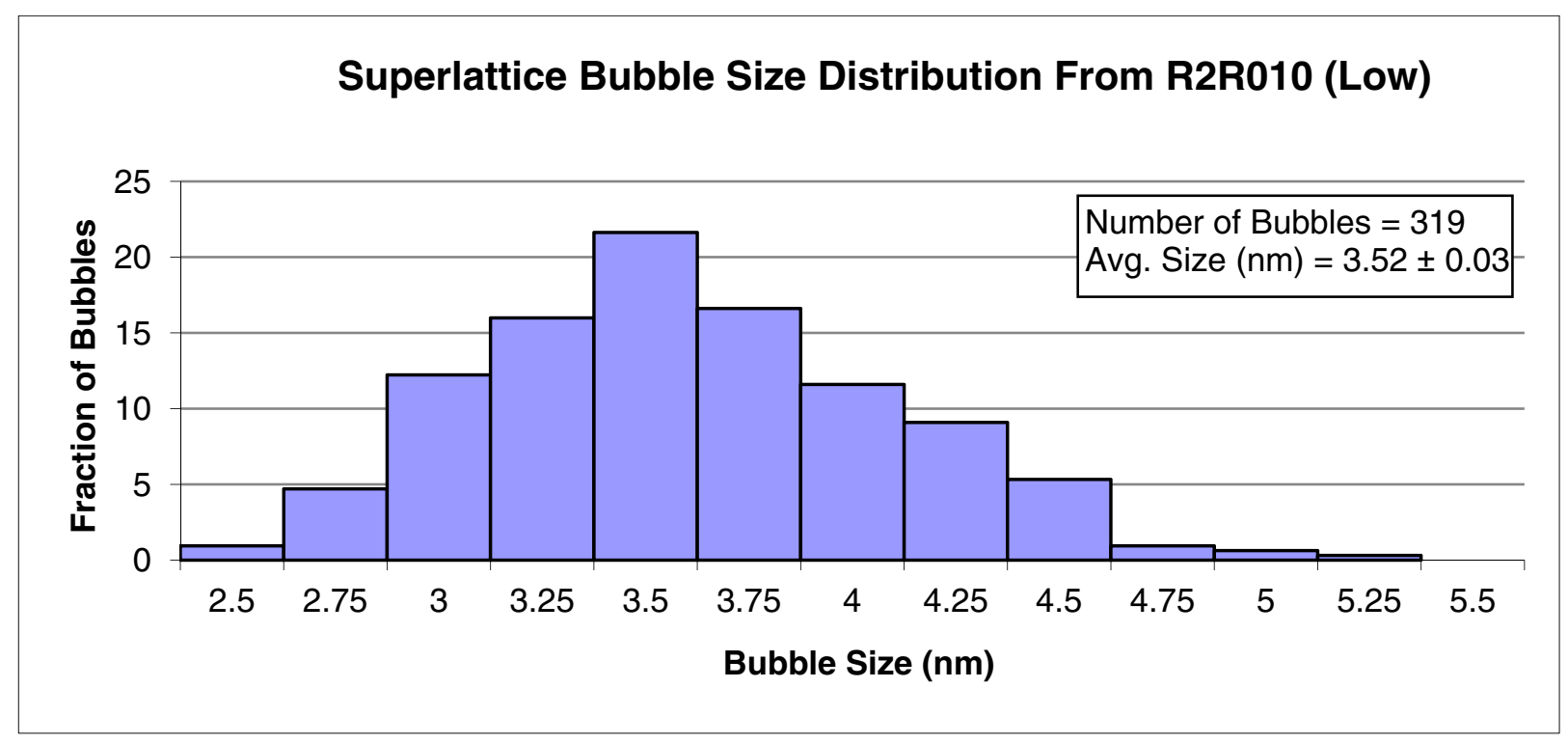

Figure 4: Superlattice bubble size distribution from plate R2R010 at a fission density of $4.5 \times 10^{21}$ fiss $/ \mathrm{cm}^{3}$ [31].

Using a $300 \mathrm{keV}$ Technai TF30-FEG STwin STEM with an electron-beam spot size of $1 \mathrm{~nm}$, energy dispersive spectroscopy (EDS) spot and map analyses were performed over a bubble superlattice area in an attempt to identify the gaseous fission products present in the bubble superlattice. The presence of $\mathrm{Kr}$ or Xe could not be definitively confirmed in the bubbles. In addition, the presence of solid fission products within the area showing superlattice bubbles was investigated. It is been hypothesized that due to very large pressures in the bubbles, any Xe or $\mathrm{Kr}$ that may be present could actually be in the solid form. Due to the small bubbles size and the stacking issue, the presence of solid fission products within the area of bubble superlattice could not be confirmed or ruled out.

TEM characterization of sample R3R050 (high) with a fission density of $5.2 \times 10^{21} \mathrm{fiss} / \mathrm{cm}^{3}$ showed that the majority of the bubble superlattice has collapsed, producing a microstructure with grains now subdivided to $100-500 \mathrm{~nm}$ in size. The resulting microstructure is primarily comprised of fission-gas bubbles that are $0.1-1.0 \mu \mathrm{m}$ in size, uniformly distributed throughout the fuel. A representative highfission-density gas bubble microstructure from sample R3R050 (high) can be seen in Figure 5a). In some areas of the fuel, there are residual micron-sized fuel grains present. In these grains, the bubble superlattice microstructure is still present in areas that show grain sizes larger than $500 \mathrm{~nm}$. This can be seen in Figure 5b) from sample R3R050 (high). Figure 5b) also shows a fission gas bubble on the grain 
boundaries of the fuel. Using energy dispersive spectroscopy (EDS), attempts to separate chemically the Mo content between a residual fuel grain and a decomposed fuel grain were performed. No significant difference between the two regions could be seen. One key observation in Figure 5a) is the presence of solid fission products inside the pores/gas bubbles. At fission densities lower than $4.5 \times 10^{21} \mathrm{fiss} / \mathrm{cm}^{3}$; these features were not seen in the bulk of the fuel grains, indicating that they are likely in solution and precipitate in the pores/gas bubbles once grain sub-division begins at fission densities greater than $4.5 \times 10^{21} \mathrm{fiss} / \mathrm{cm}^{3}$.

a)

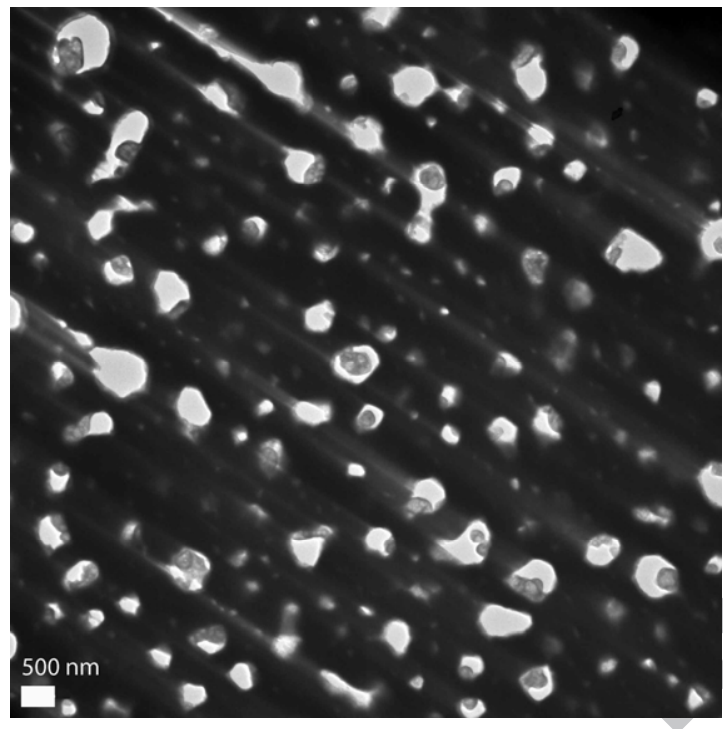

b)

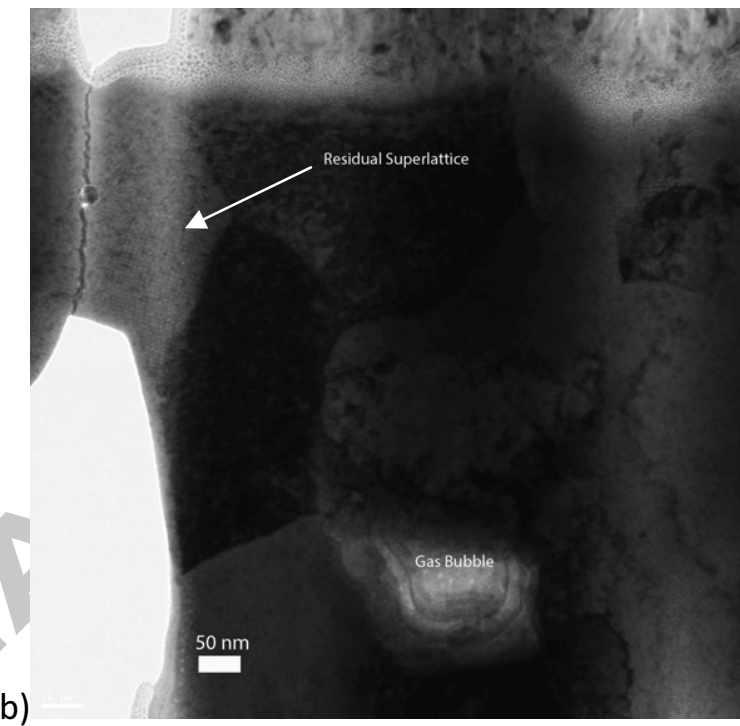

Figure 5: a) Bright field micrograph showing a typical high fission density microstructure from R3R050 (high) and b) a bright field micrograph showing residual bubble superlattice in the micron sized grains in R3R050 (high)

\section{Discussion:}

\section{A Mechanism on how the Bubble Superlattice Forms}

To date, a clear mechanism for bubble superlattice formation has not been identified. It has been demonstrated that at a fission density of $3 \times 10^{21} \mathrm{fiss} / \mathrm{cm}^{3}$, the superlattice bubble diameter appears to have already saturated. Van den Berghe [4] has shown that at a fission density of $1.3 \times 10^{21} \mathrm{fiss} / \mathrm{cm}^{3}$, the bubble superlattice appears to be fully ordered. To better understand how the bubble superlattice forms, low-fission-density irradiation experiments $\left(<1.3 \times 10^{21} \mathrm{fiss} / \mathrm{cm}^{3}\right)$ will be needed to investigate the initiation and development of the bubble superlattice. It is assumed that the bubbles are faceted due to the crystalline nature of the U-7wt\%Mo fuel. Attempts to show whether the bubbles were faceted were unsuccessful due to the effect of bubble stacking. P. B. Johnson was able to show that bubbles were faceted in ion-irradiated vanadium [15]. The faceted nature of the bubbles could play a major role in how the superlattice forms. Theories on bubble superlattice formation are briefly discussed in $[15,32,33]$ with three possibilities being 1) elastic interaction between bubbles, 2) planar diffusion of host interstitial atoms, and 3) dislocation loop punching from over-pressurized bubbles. 


\section{Physical Properties of the Bubble Superlattice}

Using Tables 1 and 2, the characteristics of the bubble superlattice can be compared to various irradiation parameters, such as fission densities, fission rates, and temperatures, to observe the effects on the size of the bubbles in the superlattice. Three samples that show a fully matured superlattice are R3R050 (low), R2R040 (low), and R2R010. For these samples, the fission rate and temperature are quite comparable, and these irradiation parameters appear to have no strong effect on the bubble superlattice. Comparing the fission densities of these samples and their respective superlattice bubble sizes, the bubbles show little to no change. This indicates that fission density has little effect at the fission densities seen by the characterized samples. It is expected that at lower fission densities, the bubble size will be heavily dependent on fission density. Characterization of the bubble superlattice by Van den Berghe showed that the bubble superlattice has fully formed in U-7wt\%Mo at a fission density of $1.3 \times 10^{21}$ fiss $/ \mathrm{cm}^{3}$ [4]. Superlattice bubble size diameters were not reported, making the comparison of the superlattice bubble size diameters at a fission density of $1.3 \times 10^{21} \mathrm{fiss} / \mathrm{cm}^{3}$ to the samples analyzed at the INL at fission densities greater than $3 \times 10^{21} \mathrm{fiss} / \mathrm{cm}^{3}$ not applicable. It is unknown where the bubble size saturation point of the bubble superlattice occurs, but it occurs at a fission density less than $3 \times 10^{21} \mathrm{fiss} / \mathrm{cm}^{3}$.

SEM characterization shows a significant difference in the intergranular fission gas bubble morphology with increasing fission densities [34]. As the fission density increases in the fuel, there is an increased density of fission-gas bubbles on the boundaries, along with an increase in the intergranular fission-gasbubble size. The likely driving mechanism of the increase in intergranular bubble density and size is the increase in fission gas inventory due to increasing burnup and the saturation of the bubble superlattice. With little to no change in the average superlattice bubble diameter, the created fission gas will be driven to other microstructural locations in the fuel, i.e. in solution and/or to the grain boundaries.

One of the key observations about the bubble superlattice in irradiated U-Mo fuel is the fact that it has an fcc structure while the $U-7 w t \% M o$ fuel has a bcc structure. For superlattices generated using ion implantations, the created superlattice has a structure that is typically the same as the host material $[14,17,22,24]$. In a few cases, a variation was seen in the bubble superlattice orientation, indicating that the bubble superlattice can have a different orientation than the host material's structure $[14,20,24]$. In the $\mathrm{U}-7 \mathrm{wt} \% \mathrm{Mo}$ fuel, no variants were seen, and all TEM results indicate that bubbles will likely form an fcc bubble superlattice structure in the host bcc U-7wt\%Mo fuel. Based on a review of the literature, the $\mathrm{U}-7 \mathrm{wt} \% \mathrm{Mo}$ is the first material that exhibits an fcc bubble superlattice in the host bcc material. Another attribute of the bubble superlattice in the $\mathrm{U}-7 \mathrm{wt} \% \mathrm{Mo}$ fuel is the fact that it is highly ordered over length scales that reach microns in length, while the ion-implanted material has shown only short range ordering of bubbles on the tens of nanometers. Consequently, the long range ordering provides an opportunity to perform more detailed characterization of the bubble superlattice compared to ionirradiated materials.

One key question to be answered about the bubble superlattice is whether the superlattice is a bubble superlattice or a void superlattice, where a bubble is filled with gas and void has no gas. Attempts were made to try and perform EDS measurements on a single column of bubbles in the superlattice to confirm the fact that the bubbles were filled with some fission gas, such as $\mathrm{Kr}$ or Xe. Attempts were unsuccessful in getting a significant signal from these bubbles to prove that they are indeed bubbles filled with $\mathrm{Kr}$ or Xe. Ghoniem compiled various works of bubble and void superlattices for comparison of irradiation conditions and when each superlattice likely formed [23]. Typical bubble and void sizes/diameters tend to be very similar. The spacing of the void and bubble lattices typically differ by an order of magnitude, with bubble superlattices between 4 and $12 \mathrm{~nm}$ while void superlattices range 
between 20 and $145 \mathrm{~nm}$. Typical implantation temperatures vary for both as well. Bubble superlattices typically form at temperatures below $0.3 T_{m}$, where $T_{m}$ is the melting temperature of the material. Void superlattices are often formed at the peak swelling temperature. The irradiation temperature for U$7 \mathrm{wt} \%$ Mo dispersion fuel is lower than the expected void formation range for a material $\left(0.3-0.6 \mathrm{~T}_{\mathrm{m}}\right)$ [35]. For $\mathrm{U}-7 \mathrm{wt} \% \mathrm{Mo}$, the irradiation temperatures vary between 373 and $423 \mathrm{~K}$, which is $0.26-0.30 \mathrm{~T}_{\mathrm{m}}$ of $\mathrm{U}-$ $7 \mathrm{wt} \% \mathrm{Mo}\left(\mathrm{T}_{\mathrm{m}}=1404 \mathrm{~K}\right)[30]$.

\section{Grain Sub-Division and Collapse of the Bubble Superlattice}

The U-7wt\%Mo fuel appears to undergo a grain sub-division process at a fission density near $4.5 \times 10^{21} \mathrm{fiss} / \mathrm{cm}^{3}$. This results in the collapse of the majority of the bubble superlattice and the formation of fuel grains roughly 100-500 $\mathrm{nm}$ in size. In addition, larger micron-sized bubbles populate the grain boundaries with solid fission products accumulating inside of these bubbles. The presence of these solid fission products and the resulting stored solution energy could introduce a possible mechanism for the grain sub-division process. The microstructure that forms due to the grain sub-division process seen in $\mathrm{U}-7 \mathrm{wt} \% \mathrm{Mo}$ is similar to the rim structure that is produced due to recrystallization of $\mathrm{UO}_{2}$. The rim structure is the outside periphery of the $\mathrm{UO}_{2}$ fuel pellets. It consists of sub-micron fuel grains with a high density of micron-sized fission-gas bubbles along the grain boundaries [36]. It should be noted that $\mathrm{UO}_{2}$ is a ceramic fuel, a completely different fuel system than the metallic form of U-7wt\%Mo. This being said, there are similarities between the two fuel systems. Defect type production could be similar between the $\mathrm{U}-7 \mathrm{wt} \% \mathrm{Mo}$ metallic fuel and the rim structure in the $\mathrm{UO}_{2}$ due to their ratio of irradiation temperature to melting temperature. The melting temperature used for $\mathrm{U}-7 \mathrm{wt} \% \mathrm{Mo}$ and irradiated $\mathrm{UO}_{2}$ was 1404 and $3122^{\circ} \mathrm{K}[30,37]$. Using an irradiation temperature of $130^{\circ} \mathrm{C}$ for $\mathrm{U}-7 \mathrm{wt} \% \mathrm{Mo}$, a ratio of $0.29 \mathrm{~T}_{\mathrm{m}}$ is found. Irradiation temperatures in the rim structure of $\mathrm{UO}_{2}$ can vary with different irradiation parameters but the rim region of the $\mathrm{UO}_{2}$ fuel has been observed in temperatures ranges from 380-1200 ${ }^{\circ} \mathrm{C}[38,39]$. This leads to a ratio between $0.21-0.47 \mathrm{~T}_{\mathrm{m}}$. The outer periphery of the $\mathrm{UO}_{2}$ fuel should have a similar defect production as the U-7wt\%Mo fuel at $130^{\circ} \mathrm{C}$.

A proposed mechanism for the recrystallization process in the rim structure is related to the stored energy of the fission products in solution in the $\mathrm{UO}_{2}$ fuel. A single atom of $\mathrm{Xe}$ in $\mathrm{UO}_{2}$ can have about 9.5 $\mathrm{eV}$ in solution energy [40]. Assuming a 2.4 at\% concentration of $\mathrm{Xe}$ in the $\mathrm{UO}_{2}$ fuel, the stored energy in the fuel would be about $20 \mathrm{~kJ}$ per mole of fuel if all Xe atoms were kept in solution. This solution energy is high compared to what likely happens in experimental $\mathrm{U}-\mathrm{Mo}$ and $\mathrm{UO}_{2}$ fuels. Experimental results show that there are nanometer-sized bubbles of $\mathrm{Xe}$ and $\mathrm{Kr}$ throughout the fuels. These nanometer-sized bubbles lower the total solution energy of the fuel grain, delaying the effects of recrystallization in U$\mathrm{Mo}$ or $\mathrm{UO}_{2}$ fuel driven by $\mathrm{Xe}$ and $\mathrm{Kr}$. In general, for cold-worked metal samples, recrystallization occurs at solution energies of $20 \mathrm{~J} / \mathrm{mol}$ [41], orders of magnitude under the proposed solution energy of Xe in $\mathrm{UO}_{2}$. Using solution energies of various fission products seen in [42] and, assuming fission product concentrations similar to $\mathrm{Xe}$, it would be expected that $\mathrm{UO}_{2}$ would undergo recrystallization at the lower temperature rim area at low to intermediate burnup. It should be noted that temperature has a major effect on defect mobility, which will lead to defect clustering that greatly reduces the solution energy of the grains and, thus, lead to no recrystallization in $\mathrm{UO}_{2}$ at higher temperature regions in the fuel.

In the studied low burnup U-7wt\%Mo dispersion fuels, irradiation temperatures are less than $150^{\circ} \mathrm{C}$, leading to low defect mobility in the fuel and, thus, to solid fission products remaining as single atom or indiscernible defect clusters $(<2 \mathrm{~nm})$ not seen by TEM characterization. The single atom/defect cluster leads to higher solution energies in the fuel. This potentially could be a mechanism that explains why grain sub-division occurs at $\sim 4.5 \times 10^{21} \mathrm{fiss} / \mathrm{cm}^{3}$. When the fission-product concentration reaches solution energy greater than that the $\mathrm{U}-7 \mathrm{wt} \% \mathrm{Mo}$ can store, it results in the grain sub-division of the fuel, which 
lowers the internal energy of the fuel grains by significantly increasing the grain boundary area. This likely instigates the release of the superlattice fission gas to the grain boundaries, where the released fission gas becomes the micron-sized fission-gas bubbles seen in the high-burnup microstructure. Additionally, the solid fission products that were in solution now diffuse readily-to the high density of grain boundaries - and cluster into larger solid-fission-product phases, like the ones seen in the highburnup microstructure of the U-7wt\%Mo fuel.

There are likely two competing factors that potentially affect the grain sub-division process: the Mo composition of the fuel and the original grain sizes in the fuel. Hofman showed that increased Mo content in the fuel has been shown to delay the onset of gamma-phase decomposition [43]. Hofman also indicated that grain boundaries heterogeneously decompose from the gamma phase to $\mathrm{U}_{2} \mathrm{Mo}$ and $\alpha-U$. Leenaers has shown that the grain boundaries of the U-Mo dispersion fuel are often have depleted Mo content (up to $2 \mathrm{wt} \%$ ) along the grain boundaries [44]. As seen in the results presented in this paper, large fission-gas bubbles start to form on these grain boundaries and appear to consume the fuel grain radially, indicating that either the low Mo content or formation of $\mathrm{U}_{2} \mathrm{Mo}$ and $\alpha-U$ phases on these boundaries may act as a sink for fission gas. TEM EDS measurements were unsuccessful in seeing a Mo content difference across residual fuel grains though the error of EDS in the TEM can be a few wt\%.

Additional investigations are needed on the $\mathrm{U}-10 \mathrm{wt} \% \mathrm{Mo}$ monolithic fuel, as the fuel appears to not undergo breakaway swelling until much later than $4.5 \times 10^{21} \mathrm{fiss} / \mathrm{cm}^{3}$. Confirmation of this delayed breakaway swelling is needed, and if the delay is present, what factors-such as the grain sizes in the monolithic fuel and/or the increased Mo content-affect the swelling-i.e. grain sub-division.

Additionally, microstructural analysis is necessary on U-10wt\%Mo dispersion fuel samples with fission densities greater than $4.5 \times 10^{21}$ fiss $/ \mathrm{cm}^{3}$ to better understand the effects of grain size and/or Mo content. Understanding the effect of Mo content in the $\mathrm{U}-10 \mathrm{wt} \% \mathrm{Mo}$ will help better understand the irradiation behavior of U-7wt\%Mo fuel.

\section{Conclusions:}

TEM characterization of the ordered bubble superlattice shows that it is coherent with the host material, forming a face centered cubic structure, not isomorphic to the bcc structure of the U-Mo. TEM samples were analyzed at various irradiation conditions to understand the effect of irradiation parameters on the bubble superlattice. It appears that fission rate and irradiation temperatures do not play any strong role on the bubble superlattice. Microstructural characterization shows that the bubble superlattice has reached a saturated state by a fission density of $3 \times 10^{21} \mathrm{fiss} / \mathrm{cm}^{3}$. There are few to no changes in the size of the bubble superlattice size up to a fission density of $4.5 \times 10^{21} \mathrm{fiss} / \mathrm{cm}^{3}$. An increased density and size of the intergranular bubbles are seen along the grain boundaries of the fuel with increasing burnup, indicating that the new fission gas created during burnup is likely driven to the grain boundaries. Various mechanisms describing how the bubble superlattice forms and fails were presented. Comparisons between void and bubble superlattices were made and it was determined that the superlattice in $\mathrm{U}-7 \mathrm{wt} \% \mathrm{Mo}$ is most likely a bubble superlattice with fission gases stabilizing the bubbles.

At a fission density of $4.5 \times 10^{21} \mathrm{fiss} / \mathrm{cm}^{3}$, the majority of the $\mathrm{U}-7 \mathrm{wt} \% \mathrm{Mo}$ fuel has undergone grain subdivision and is no longer able to support the bubble superlattice. The fuel has now a refined grain structure with most grains less than $500 \mathrm{~nm}$ in size. In grains larger than $500 \mathrm{~nm}$, the bubble superlattice can still be present, indicating that the stability of the grains themselves likely drives the stability of the bubble superlattice and the grain subdivision process. This stability might be related to higher Mo content of the grains and/or larger fuel grains. The fission gas, no longer in the superlattice bubbles, has 
now coalesced into larger sub-micron-sized bubbles, uniformly distributed throughout the fuel. Solid fission product precipitates decorate these grain-boundary fission-gas bubbles.

\section{Acknowledgments:}

This manuscript has been authored by Battelle Energy Alliance, LLC, under Contract No.

DE-AC07-05ID14517 with the U.S. Department of Energy. The U.S. Government retains and the publisher, by accepting the article for publication, acknowledges that the U.S. Government retains a nonexclusive, paid-up, irrevocable, world-wide license to publish or reproduce the published form of this manuscript, or allow others to do so, for U.S. Government purposes.

\section{U.S. Department of Energy Disclaimer:}

This information was prepared as an account of work sponsored by an agency of the U.S. Government. Neither the U.S. Government nor any agency thereof, nor any of their employees, makes any warranty, express or implied, or assumes any legal liability or responsibility for the accuracy, completeness, or usefulness of any information, apparatus, product, or process disclosed, or represents that its use would not infringe privately owned rights. References herein to any specific commercial product, process, or service by trade name, trademark, manufacturer, or otherwise, does not necessarily constitute or imply its endorsement, recommendation, or favoring by the U.S. Government or any agency thereof. The views and opinions of authors expressed herein do not necessarily state or reflect those of the U.S. Government or any agency thereof.

[1] D. M. Wachs, D. D. Keiser Jr., M. K. Meyer, D. E. Burkes, C. L. Clark, G. A. Morre, J.F. Jue, T. Totev, G. L. Hofman, T. C. Wiencek, Y. S. Kim, J. L. Snelgrove. Boise ID : s.n., 2007.

[2] D. D. Keiser Jr., J. Jue, A. B. Robinson, P. Medvedev, J. Gan, B. D. Miller, D. M. Wachs, G. A. Moore, C. R. Clark, M. K. Meyer, and M. Ross Finlay, "Effects of irradiation on the microstructure of U-7Mo dispersion fuel with Al-2Si matrix," Journal of Nuclear Materials. 425 (2012) 156-172.

[3] J.F. Jue, D. D. Keiser, Jr., C. R. Breckenridge, G. A. Moore, and M. K. Meyer, "Microstructural characteristics of HIP-bonded monolithic nuclear fuels." Journal of Nuclear Materials. 448 (2014) 250-258.

[4] S. Van den Berghe, W. Van Renterghem, A. Leenaers. "Transmission electron microscopy investigation of irradiated U-7wt\%Mo dispersion fuel" Journal of Nuclear Materials 375 (2008), pp. 340-346.

[5] J. Allenou, H. Plancher, X. Iltis, M. Cornen, O. Tougait, R. Tucoulou, E. Welcomme, Ph. Martin, C. Valot, F. Charollais, M. C. Anselmet, P. Lemoine. "U-Mo/Al-Si interaction: Influence of Si concentration" Journal of Nuclear Materials 399 (2010), pp. 189-199.

[6] J. Gan, D. D. Keiser Jr., D. M. Wachs, A. B. Robinson, B. D. Miller, T. R. Allen. "Transmission electron microscopy characterization of irradiated U-7Mo/Al-2Si dispersion fuel." Journal of Nuclear Materials 396 (2010), pp. 234-239.

[7] Y. S. Kim, J. M. Park, H. J. Ryu, Y. H. Jung, G. L. Hofman. "Reduced interaction layer growth of U-Mo dispersion in Al-Si" Journal of Nuclear Materials 430 (2012), pp. 50-57.

[8] A. Leenaers, S. Van den Berghe, C. Detavernier. "AlSi matrices for U(Mo) dispersion fuel plates" Journal of Nuclear Materials 439 (2013), pp. 7-18.

[9] J. Gan, D. D. Keiser Jr., B. D. Miller, A. B. Robinson, J. F. Jue, P. Medvedev, D. M. Wachs. "TEM characterization of U-7Mo/Al-2Si dispersion fuel irradiated to intermediate and high fission densities" Journal of Nuclear Materials 424 (2012), pp. 43-50. 
[10] S. Van den Berghe, Y. Parthoens, G. Cornelis, A. Leenaers, E. Koonen, V. Kuzminov, C. Detavernier. "Swelling of $\mathrm{U}(\mathrm{Mo})$ dispersion fuel under irradiation-non-destructive analyses of the SELENIUM plates" Journal of Nuclear Materials 442 (2013), pp. 60-68.

[11] S. Van den Berghe, Y. Pathoens, F. Charollais, Y. S. Kim, A. Leenaers, E. Koonen, V. Kuzminov, P. Lemoine, C. Jarousse, H. Guyon, D. Wachs, D. Keiser Jr., A. Robinson, J. Stevens, G. Hofman. "Swelling of U(Mo)-Al(Si) dispersion fuel under irradiation-non-destructive analyses of the LEONIDAS E-FUTURE plates" Journal of Nuclear Materials 430 (2012), pp. 246-258.

[12] Y. S. Kim, G. L. Hofman. "Fission product induced swelling of U-Mo alloy fuel" Journal of Nuclear Materials. 419 (2011), pp. 291-301.

[13] D. J. Mazey, J. H. Evans. "Bubble lattice formation in titanium injected with krypton ions" Journal of Nuclear Materials 138 (1986), pp. 16-18.

[14] P. B. Johnson, F. Lawson. "Helium gas-bubble superlattice formation in molybdenum" Nuclear Instruments and Methods in Physics Research B 243 (2006), pp. 325-334.

[15] P. B. Johnson, K. J. Stevens, R. W. Thompson. "Image processing techniques in the study of ordered bubble arrays: Bubble facetting in vanadium" Nuclear Instruments and Methods in Physics Research B 62 (1991), pp. 218-227.

[16] J. H. Evans, D. J. Mazey. "Solid bubble formation in titanium injected with krypton ions" Journal of Nuclear Materials 138 (1986), pp. 176-184.

[17] P. B. Johnson, D. J. Mazey. "The gas-bubble superlattice and the development of surface structure in He+ and H+ irradiated metals at 300K" Journal of Nuclear Materials 93 and 94 (1980), pp. 721727.

[18] P. B. Johnson, D. J. Mazey. "Hydrogen gas-bubble structure in proton-irradiated copper at 300K" Journal of Nuclear Materials 91 (1980), pp. 41-46.

[19] F. E. Lawson, P. B. Johnson. "A temperature threshold for gas-bubble superlattice formation in molybdenum" Journal of Nuclear Materials 252 (1998), pp. 34-42.

[20] P. B. Johnson, A. L. Diprose, D. J. Mazey. "The He gas bubble superlattice in Cu: Analysis of structural variants in [110] grains" Journal of Nuclear Materials 158 (1988), pp. 108-118.

[21] Evans, J. H. "Void and bubble lattice formation in molybdenum: A mechanism based on twodimensional self-interstitial diffusion" Journal of Nuclear Materials 119 (1983), pp. 180-188.

[22] P. B. Johnson, D. J.Mazey. "Gas-bubble superlattice formation in bcc metals" Journal of Nuclear Materials 218 (1995), pp. 273-288.

[23] N. M. Ghoniem, D. Walgraef, S. J. Zinkle. "Theory and experiment of nanostructure selforganization in irradiated metals" Journal of Computer-Aided Materials Design 8 (2002), pp. 1-38.

[24] P. B. Johnson, D. J. Mazey. "A helium gas-bubble superlattice in vanadium with bubble concentrations unprecedented for metals" Journal of Nuclear Materials 170 (1990), pp. 290-293.

[25] D. E. Janney, A. B. Robinson, T. P. O'holleran, R. P. Lind, M. Babock, L. C. Brower, J. Jacobs, P. K. Hoggan. "Post-irradiation-examination of irradiated fuel outside the hot cell" HOTLAB-2007 Proceedings of the Hat Laboratories and Remote Handling Working Group, Bucharest, Romania.

[26] B. D. Miller, J. Gan, J. Madden, J. F. Jue, A. Robinson, D. D. Keiser Jr. "Advantages and disadvantages of using a focused ion beam to prepare TEM samples from irradiated U-10Mo monolithic fuel" Journal of Nuclear Materials 424 (2012), pp. 38-42.

[27] J. Gan, D. D. Keiser Jr., D. M. Wachs, A. B. Robinson, B. D. Miller, T. R. Allen. "TEM characterization of irradiated RERTR dispersion fuel," RRFM European Reactor Conference 2009 Transactions. The Thirteenth International Topical Meeting on Research Reactor Fuel Management, Vienna, Austria.

[28] D. D. Keiser Jr., A. B. Robinson, D. E. Janney, J. F. Jue. "Results of recent microstructural characterization of irradiated U-Mo dispersion fuels with Al alloy matrices that contain Si," RRFM European Reactor Conference 2008 Transactions. The Twelfth International Topical Meeting on Research Reactor Fuel Management, Hamburg, Germany. 
[29] J. Gan, B. D. Miller, D. Keiser Jr., A. Robinson, J. Madden, P. Medvedev, D. Wachs. "TEM Characterization of High Burn-up Microstructure of U-7Mo Alloy" RRFM European Reactor Conference 2014 Transactions. The 2014 International Research Reactor Fuel Management Conference, Ljubljana, Slovenia.

[30] J. Rest, Y. S. Kim, G. L. Hofman, M. K. Meyer, S. L. Hayes. U-Mo Fuels Handbook, Version 1. RERTRANL. June 2006.

[31] B. Miller, D. Keiser Jr., J. Gan, J. Jue, A. Robinson, P. Medvedev, M. Meyer, D. Wachs. "U-7Mo alloy microstructural evolution during irradiation," RRFM European Reactor Conference 2013 Transactions. The Seventeenth International Topical Meeting on Research Reactor Fuel Management, St. Petersburg, Russia.

[32] W. G. Wofer. "Dislocation loop punching in bubble arrays" Philosophical Magazine A 59 (1989), pp. 87-103.

[33] W. G. Wofer. "The pressure for dislocation loop punching by a single bubble" Philosophical Magazine A 58 (1988), pp. 285-297.

[34] Y. S. Kim, G. L. Hofman, J. S. Cheon. "Recrystallization and fission-gas-bubble swelling of U-Mo fuel" Journal of Nuclear Materials 436 (2013), pp. 14-22.

[35] S. J. Zinkle, J. T. Busby. "Structural materials for fission and fusion energy" Materials Today 11 (2009), pp. 12-19.

[36] L. E. Thomas, C. E. Beyer, L. A. Charlot. “Microstructural analysis of LWR spent fuels at high burnup” Journal of Nuclear Materials 188 (1992), pp. 80-89.

[37] S. Yamanouchi, T. Tachibana, "Melting temperature of irradiated $\mathrm{UO}_{2}$ and $\mathrm{UO}_{2}-2 \mathrm{wt} \% \mathrm{Gd}_{2} \mathrm{O}_{3}$ fuel pellets up to a burnup of about $30 \mathrm{GWd} / \mathrm{tU}$," Journal of Nuclear Science and Technology 25 (1988), pp.528-533.

[39] I. L. F. Ray, Hj. Matzke, H. A. Thiele, M. Kinoshita. "An electron microscopy study of the RIM structure of a $\mathrm{UO}_{2}$ fuel with a high burnup of 7.9\% FIMA," Journal of Nuclear Materials 245 (1997) pp. 115-123.

[40] L. E. Thomas, C. E. Beyer, L. A. Charlot. "Microstructural analysis of LWR spent fuels at high burnup," Journal of Nuclear Materials 188 (1992) pp. 80-89.

[41] L. M. Clarebrough, M. E. Hargreaves, M. H. Loretto. Recovery and Recrystallization of Metals. New York: Interscience, 1963.

[42] J-P Crocombette. "Ab initio energetics of some fission products ( $\mathrm{Kr}, \mathrm{I}, \mathrm{Cs}$, Sr, and $\mathrm{He})$ in uranium dioxide" Journal of Nuclear Materials 305 (2002), pp. 29-36.

[43] G. L. Hofman, M. K. Meyer. "Design of high density gamma-phase uranium alloys for LEU dispersion fuel applications." RERTR-1998, The 1998 International Reduced Enrichment for Test Reactor Conference, Sao Paulo, Brazil.

[44] A. Leenaers, S. Van den Berghe, E. Koonen, C. Jarousse, F. Huet, M. Trotabas, M. Boyard, S. Guillot, L. Sannen, M. Verwerft. "Post-irradiation examination of uranium-7wt\% molybdenum atomized dispersion fuel" Journal of Nuclear Materials 335 (2004), pp. 39-47. 